\title{
Economic Growth and Convergence in Latin America
}

By

STEPHEN DOBSON*

$\&$

CARLYN RAMLOGAN^ $\wedge$

* School of Management and Economics, The Queen’s University of Belfast, UK

$\wedge$ Department of Agricultural and Food Economics, The Queen’s University of Belfast, UK

Address for Correspondence:

Stephen Dobson

School of Management and Economics

The Queen's University of Belfast

Belfast

BT7 1NN

UK

Email: s.dobson@qub.ac.uk

Length of article: 8114 words (including notes and references) 


\section{Economic Growth and Convergence in Latin America}

Little is known about the convergence process among developing countries in general and in Latin America in particular. For the period as a whole there is no evidence of a narrowing in the cross-country dispersion of income (sigma convergence). But there is evidence of convergence to different steady state income levels at a speed that is common to all countries (conditional beta convergence). The paper also shows that the estimates of convergence are sensitive to the way in which GDP per capita is measured.

\section{INTRODUCTION}

The question of whether the per capita incomes of different countries or regions are converging over time has become a central topic for economists interested in economic growth. In the neo-classical growth model the per capita growth rate tends to be inversely related to the starting level of income per capita. Countries are said to converge to their balanced growth paths. Therefore, to the extent that differences in output/worker arise from countries being at different points relative to their balanced growth paths, poorer countries will grow faster than richer ones if countries are similar with respect to preferences and technology ${ }^{1}$. Early empirical tests of the convergence hypothesis found robust evidence of convergence for a given quantity of human capital poorer countries (or regions) are growing faster than richer ones [Barro, 1991; Barro and Sala-i-Martin, 1991, 1992; Baumol, 1986; Mankiw et al, 1992]. But in more recent studies the evidence is mixed. Sala-i-Martin [1996a, 1996b] finds evidence of convergence among OECD countries, states in the US and regions in Europe and Japan while Persson [1997] finds strong support for the convergence hypothesis in Sweden. However, studies of Austria [ 1997] and Italy [Terrasi, 1999] find little evidence of convergence. A review of the convergence literature may be found in de la Fuente [2000].

This paper aims to contribute to the debate by examining the convergence hypothesis for Latin America ${ }^{2}$. Little is known about the convergence process among developing countries in general and in Latin America in particular. Although Khan and Kumar [ $\underline{1993}]$ test the convergence hypothesis among 95 
developing countries in Africa, Asia, Europe (including the Middle East) and Latin America, their results are presented in an aggregate form. This means it is not possible to identify the process of convergence among a group of developing countries that are located in one particular region of the world (such as Latin America). Studies of developing country convergence have tended to concentrate on convergence within a country. For example, Ferreira [2000] finds strong evidence of regional convergence in Brazil, while Nagaraj et al [2000] and Choi and Li [2000] identify per capita income convergence in India and China, respectively.

The concept of convergence is important because it can inform policy makers of the need, or otherwise, for development policies to promote equity and growth. If countries are converging over time, economic disparities between nations may diminish naturally. It then becomes harder to justify a regional development policy in terms of economic efficiency. On the other hand, an absence of convergence (or convergence at a very slow pace) suggests the need for proactive policies in order to promote growth and reduce income inequalities [Neven and Gouyette, 1995]. In Latin America a number of regional development associations have been formed (for example, the Latin American Free Trade Association and the Latin American Integration Association) to deal, among other things, with inter country income disparities, but up to now little is known about the convergence process in this region.

The study also considers an issue that has tended to be overlooked in the convergence literature - the extent to which convergence estimates are sensitive to the way in which per capita GDP is measured. A number of alternative sources of data are available for a study of this nature but they do not all define GDP in the same way. Typically, cross-country convergence studies have used data provided by Summers and Heston (SH). The SH income data adjusts for cross-country differences in the cost of living by using observed prices of goods and services. This series ends in 1990 for Latin American countries. In order to provide more recent evidence (up to 1997) data from the United Nations (UN) is also used. The UN data, in contrast, is based on domestic GDP figures and market exchange rates to compare the values of GDP across countries. The implications of the differences in GDP measurement are considered in Section IV when the convergence estimates are compared using these two alternative data sources. 
The outline of the paper is as follows. Section II places the study in its Latin American context by considering the implications for convergence of certain aspects of the region's growth performance between 1960 and 1990. In particular, observations on changes in the rankings of countries in terms of real per capita GDP are linked to certain aspects of policy which may have assisted or hampered convergence. In Section III the rationale for convergence is explained and the empirical methodology is described. Section IV presents the results. The final section offers some concluding remarks.

\section{THE LATIN AMERICA CONTEXT}

The countries of Latin America have experienced periods of both steady growth and economic decline since 1960. While the region grew at around two per cent per year on average in the 1960s and 1970s real growth rates were negative in most countries during the 1980s. While growth over the period as a whole has been steady it has been modest in comparison with some other developing regions (notably Asia). But what is of more interest is whether the growth is converging - has the growth experience been shared equally across the region to the extent that the fastest growth has taken place in the countries that were relatively poor at the start of the study period? As a prelude to the formal examination of convergence in Section IV it is also useful to conduct a more informal investigation based on per capita income data and country growth rates over the period. The aim of doing this is not to explain differences in income levels or growth rates in terms of underlying elements of policy (national or international) or circumstance, but rather point to developments which may have assisted or hindered growth and hence the process of convergence.

Table 1 reports the rank of each country by per capita real GDP at five-yearly intervals between 1960 and 1990. Annual average growth rates are also shown for each country for the overall period 1960-90. The figures in Table 1 were obtained using the SH data which measures real GDP in constant dollars expressed in international prices, with 1985 as the base year. Between 1960 and 1990 Latin America grew at an annual average rate of 1.12 per cent. Clearly this figure masks variations across countries - while countries such as Brazil, Ecuador and Mexico had averaged annual growth rates of over two per cent per 
year during the study period, others such as Haiti and Nicaragua experienced negative annual average growth rates. The rankings of countries by real per capita GDP alter relatively little over the period though there are a few notable exceptions. For example, in both Nicaragua and Peru performance deteriorated markedly in a short space of time (between 1975 and 1980). Between these years the real growth rate was negative in both countries - at five per cent per year on average in Nicaragua and 1.5 per cent per year in Peru. This had the effect of moving Nicaragua towards the bottom of the rankings and placing Peru outside of the top ten of richest nations for the first time. The final column of Table 1 summarises the movement in ranking over the period. The five richest countries in per capita income terms in 1960 (Venezuela, Argentina, Uruguay, Chile and Mexico) maintain their places in 1990 although there has been some change in their relative positions. Similarly, the three poorest countries in 1960 (Bolivia, Honduras and Haiti) occupy three of the four bottom places in 1990. Countries that were not in the top five or bottom three places in 1960 experienced a little more movement. While the deterioration in performance of Nicaragua and Peru has already been noted some other countries (Ecuador, Dominican Republic, Panama and Paraguay) improved their position quite appreciably.

Given the data in Table 1 it is pertinent to ask whether there is likely to have been convergence, in the sense of poor countries catching up rich, over this period. The data suggest possible convergence given the relatively strong growth performance of some of the poorer countries in 1960 (Ecuador and Panama for example) and the low growth rates achieved by some of the richer nations (for example, Venezuela, Argentina and Uruguay). But whatever the finding for convergence between 1960 and 1990 it is possible that convergence may be present during shorter time periods within the overall period. As Table 1 shows the rankings alter to some degree over each of the five-year periods. Between 1960 and 1965 there is no major shift in relative positions. Although both Panama and Nicaragua improved by three places on the back of strong growth to 1965 most of the richer countries held their positions and grew reasonably quickly. Although the rankings change very little in the five years to 1970 growth in the richest few countries is more modest in comparison with some of the poorer ones. In the first half of the 1970s there is little noticeable movement in the rankings but again there is fast growth in some of the poorer countries such as Ecuador and much more modest growth in some richer ones (Venezuela and Uruguay). Between 
1975 and 1980 the big losers are Peru and Nicaragua while Ecuador and Honduras among others experienced fast growth. The bigger shift in relative rankings in the 1970s suggests a stronger possibility of convergence. During the economic collapse of the 1980s many countries experienced negative real growth rates but the severity of the recession was not equally felt in all countries. Some of the richer countries in per capita income terms in 1980 suffered higher negative rates of growth than a number of the poorer countries although the shift in relative rankings was not marked in either half of the decade. The prospects for convergence do not appear strong for the 1980s as a whole.

The economic development of Latin America has often been linked to access to foreign capital. In the 1950s the region's foreign finance was heavily dependent on direct foreign investment flows and bilateral lending. World Bank funding at the end of the 1950s complemented this. More multilateral finance became available in the early 1960s with the establishment of the Inter American Development Bank. Along with the injection of foreign capital into the region, the early 1950s also saw the beginning of a programme of import substitution in many countries. The exclusion of foreign competition and the provision of bank credit and essential inputs at preferential rates boosted the policy. Governments in a number of countries also became directly involved in import substitution with the setting up of public enterprises in highly protected sectors. During the 1950s this helped speed up the process of industrialisation in the region but the impact was primarily felt in the richer countries, all of which had grown steadily between 1950 and 1960. A number of the poorest nations in 1960 grew slowly (or not at all) during the 1950s and by the mid-1960s the much hoped for boost to development in the poorer areas had failed to materialise. Import substitution tended to inhibit efficient production because little effort was made at raising domestic competitiveness and promoting technological advance [ $\underline{\text { Hoffman, 2000] }}$. But by the end of the 1960s a number of poorer countries such as Bolivia, Ecuador and Dominican Republic had achieved high rates of growth mainly due to changes to their internal structure - artisan type activities were replaced by manufacturing production [United Nations, 1985]. This suggests convergence is more likely to be found in the second half of the decade. 
The introduction of liberalisation programmes in a number of countries in the 1970s made economic and social conditions favourable for an inflow of financial resources. These foreign resources were used to further advance the process of industrialisation in a number of the richer countries where growth was reasonable, while in countries such as Ecuador and Paraguay growth was rapid during the 1970s due to the developing energy sectors. The favourable prospects for economic growth in the 1970s plus the rapid growth experienced by some of the poor countries point to positive signs for convergence. But the forces creating growth in the 1970s eventually created imbalances including the overproduction of non-traded goods, unparalleled debt and rampant price instability.

In the early 1980s Latin America suffered its severest recession since the 1930s. The combined effect of a lack of price adjustment and heavy indebtedness caused countries to grow slowly or not at all in the 1980s. In the second half of the decade growth returned to some countries but these were typically the richer ones, such as Brazil, Mexico, Chile, Columbia and Uruguay while for most of the poorer countries economic growth was insufficient to offset the effects of population growth [United Nations, 1996]. This points to a weakening of convergence from the mid-19980s. Although the structural reforms introduced in many countries in the early 1990s were successful in promoting economic expansion the relatively strong (weak) performance of some of the richer (poorer) countries does not suggest a return to convergence during the 1990s.

\section{CONCEPTUAL BACKGROUND AND EMPIRICAL METHODOLOGY}

In the neo-classical growth model the source of convergence is the assumed diminishing returns to capital. If the ratio of capital to effective labour declines relative to the steady state ratio the marginal productivity of capital rises. If the only difference across countries is their initial levels of capital, then the prediction of the model is that countries with little capital will be poor and will grow faster than rich countries with large capital stocks. In steady state these 'identical' countries will have the same per capita income [Sala-i-Martin, $\underline{1996 a]}$. With a common steady state the initially poorer countries will be unambiguously farther away from their steady state. Thus, for a given savings behaviour each country 
will tend to grow more rapidly the greater is the gap between its initial per capita income level and the steady state level ${ }^{3}$. Convergence to the same steady state income is called absolute or unconditional beta convergence.

If countries are different with regard to the level of technology, propensities to save or population growth rates the neo-classical model predicts conditional convergence. This means countries will have different steady state income levels, but after controlling for the determinants of the steady state income level, poorer countries should grow faster than richer ones [Mankiw et al, 1992]. In other words, conditional convergence says that countries will approach some long run level of income once the differences across countries are held constant and the growth rate falls as they approach the long run level. To the extent that the determinants of steady state income are similar across countries convergence is expected. In effect, the differences between countries become stationary in the long run since each country converges towards its own steady state [Sala-i-Martin, 1996a].

In 'classical' convergence studies the convention is to measure convergence in the way suggested by Barro and Sala-i-Martin [1991]. The convergence measure can be related to the transitional growth process in a neo-classical model. The transition process of output or income per capita in country i at time $\mathrm{t}\left(\mathrm{y}_{\mathrm{it}}\right)$ and over the period $\mathrm{T}$, can be approximated as:

$(1 / T) \times \log \left(y_{i t} / y_{i, t-T}\right)=x_{i}^{*}+\log \left(Y_{i}^{*} / Y_{i, t-T}\right)\left(1-e^{-\beta T}\right) \times(1 / T)+u_{i t}$

where $\mathrm{X}_{\mathrm{i}}^{*}$ is the steady state per capita growth rate, $\mathrm{Y}_{\mathrm{it}}$ is output per effective worker, $\mathrm{Y}_{\mathrm{i}}$ * is the steady state level of output per effective worker, $\beta$ is the coefficient of the rate of convergence, and $\mathrm{u}_{\mathrm{it}}$ is a disturbance term. The term $\beta$ measures the speed at which $\mathrm{Y}_{\mathrm{it}}$ approaches $\mathrm{Y}_{\mathrm{i}}{ }^{*}$. Convergence is conditional to the extent that it is affected by the steady state values $\mathrm{X}_{\mathrm{i}}{ }^{*}$ and $\mathrm{Y}_{\mathrm{i}}{ }^{*}$, which may differ across countries. To identify $\beta$ it is therefore necessary to hold constant cross-country differences in steady state values. One approach to this is to restrict the analysis to countries for which the assumption of similar steady 
states is not unrealistic, so that conditional and unconditional convergence need not be distinguished

[Sala-i-Martin, 1996a]. In other words, where technological and institutional differences across countries are believed to be small unconditional convergence may be expected.

If, however, there are 'significant' differences in technology and tastes across countries unconditional convergence is unlikely to be found. In this case it is necessary to introduce a number of conditioning variables to control for differences in steady states when estimating the following non-linear equation:

$(1 / T) \times \log \left(y_{i t} / y_{i, t-T}\right)=a-\left(1-e^{-\beta T}\right)(1 / T) \times \log \left(y_{i, t-T}\right)+u_{i t}$

If $\beta$ is positive when (2) is estimated with conditioning variables, there is conditional convergence across countries - in the long run each country is converging towards its own steady state income at a speed given by $\beta$. On the other hand, if it is assumed that the only difference between countries is the level of per capita income, then (2) is estimated without conditioning variables. In this case, a positive $\beta$ coefficient measures the rate of unconditional convergence - the speed at which countries are approaching a common steady state level of income.

Different growth models suggest different conditioning variables to proxy for the steady state. In the strict neo-classical model possible differences in the determinants of steady states may be provided by the savings rate, population growth rate and technology. A higher savings rate should lead to more rapid capital accumulation so hastening the onset of diminishing returns. Population growth is expected to speed up convergence because as the capital-labour ratio is reduced diminishing returns are expected to set in. Following Barro [1991] researchers have interpreted technology liberally with as many as 50 different conditioning variables being used in convergence regressions. In this study 'technology' is captured with two variables - one is a country dummy variable (oil exporting/non-oil exporting) and the other is a sectoral composition variable for each country. Following Barro and Sala-i-Martin [1991] this is defined as follows: 
$S_{i t}=\sum_{j=1}^{2} w_{i j, t-T} \times \log \left(y_{j t} / y_{j, t-T}\right)$

where $\mathrm{w}_{\mathrm{ij}, \mathrm{t}-\mathrm{T}}$ is the weight of sector $\mathrm{j}$ (agriculture or industry) in country i's per capita income at time t-T and $y_{\mathrm{jt}}$ is the Latin American average per capita income that originates in sector $\mathrm{j}$ at time t. This variable represents the total growth rate of per capita income in country i between years t- $\mathrm{T}$ and $\mathrm{t}$ if each of the country’s sectors grew at the Latin American average rate for that sector. The variable reflects shocks to agriculture and industry in a way that interacts with country i's concentration in those sectors that do relatively well or badly in terms of income because of the shocks. It serves as a proxy for common effects related to sectoral composition in the error term of (2). By holding constant the shocks that might affect groups of countries in common as well as the shocks that are correlated with initial per capita income, this variable is designed to help stabilise the $\beta$ coefficient across sub periods [Barro and Sala-i-Martin, $\underline{1991]}$. In the 'augmented' neo-classical model of Mankiw et al [1992] a proxy for human capital investment is also used as a conditioning variable ${ }^{4}$. If these control variables help to generate conditional convergence then countries are approaching some long run level of income that is captured by the conditioning variables and the growth rate falls as the country approaches this long run level ${ }^{5}$.

It is also common in convergence studies to measure the cross-sectional dispersion of per capita income over time. This is known as sigma convergence. This type of convergence is usually presented in terms of the standard deviation of per capita income across countries. If the standard deviation is decreasing over time there is evidence of sigma convergence. How does this relate to the idea of $\beta$ convergence? Equation (2) can be used to see that the cross-sectional dispersion in income does not necessarily decrease over time even with $\beta$ convergence because there are random shocks. At the same time as countries are converging to a steady state a new shock may temporarily increase the dispersion in income across countries. Beta convergence is therefore a necessary but not a sufficient condition for sigma convergence [Quah, 1993]. In this paper estimates of both beta and sigma convergence are provided. 
The start date and end date for the empirical analysis is determined by data availability. Even so, in a study of this nature it is important that the two dates correspond to roughly similar points in the business cycle. Hofman [2000] examines the economic development of Latin America since the early 1900s and reports annual average growth rates of around two per cent between 1950 and 1980 and for the period from 1990-95. A related issue concerns the possibility of measurement error in nominal income, especially at the start of the period [see, for example, Persson, 1997]. The end date income measure only affects the dependent variable (the growth rate) and any measurement error here will be captured in the error term. The start date income measure also affects the growth rate but since it also appears as a right hand side variable it creates the potential for bias in the estimations. To deal with potential measurement error (and in common with other researchers) different start dates may be used. As a further check on the reliability of start date income, data for a number of years prior to the start date may used (where available) to create an average income variable instead of start date income [see Barro, 1991]. In Section IV consideration is given to the use of different start (and end) dates and an average income measure (where data allows) instead of start date income.

As noted in Section I, convergence studies have paid relatively little attention to the definition of per capita GDP even though the way GDP is measured might be expected to have a marked effect on the convergence rate ${ }^{6}$. This issue is examined by estimating (2) using per capita GDP data from the SH data base and the UN Statistical Yearbook for Latin America ${ }^{7}$. The differences in the measurement of real per capita income are likely to be captured in the convergence estimates since the lower relative prices of non-traded goods in poorer countries are better reflected in the SH data [Barro and Sala-i-Martin, $\underline{1995}$ ].

Econometric issues

The test for $\beta$ convergence in (2) involves estimating a cross sectional regression. Typically, researchers have estimated $\beta$ for the sample period as a whole and for individual sub periods (usually five or ten year intervals) within the overall period. However, Islam [1995] argues that cross sectional estimation across 
countries can be problematic because it is likely that not all of the relevant conditioning variables will be included in a cross sectional regression. If there are any omitted variables this will introduce non-zero covariance between the disturbance term and the $\beta$ coefficient, rendering the estimate of the convergence parameter biased and inconsistent. It is suggested that this problem does not arise if the data is pooled and analysed using panel data methods. It can be established whether it is admissible to pool the data or whether the data should be kept separate by conducting a likelihood ratio (LR) test. Pooling the data imposes the restriction that $\beta$ is the same across each sub period. A rejection of this restriction means it is not necessary to pool the data - $\beta$ is not the same in each sub period so it is admissible to run separate cross sectional regressions. If, on the other hand, it is impossible to reject the null hypothesis that the $\beta$ values are the same, then the data should be pooled and appropriate panel methods used. Here, the null hypothesis of a common $\beta$ is rejected on every occasion so it is admissible to keep the data separate and estimate (2) using cross sectional regression (see Section IV).

Another issue concerns one of the fundamental assumptions of the classical approach to convergence, that steady state growth rates are homogeneous (countries converge to different levels of per capita GDP but at the same rate). According to Lee et al [1997] the homogeneity assumption poses a serious problem because it can lead to biased estimates of the speed of convergence. This is also true when the data is pooled and estimation is done with fixed effects. Lee et al say it is possible to overcome the problem by developing a stochastic model of growth that formalises the notion of heterogeneity - countries may converge to different levels of per capita GDP at different growth rates. In time series analysis, both trend stationary and difference stationary models strongly reject the restriction of a common technology growth rate across a large sample of countries. The results show that cross-sectional and panel estimates will not reveal rapid convergence from some initial output levels even when it is present ${ }^{8}$.

\section{RESULTS}

Table 2 reports the non-linear least squares estimates of $\beta$ for the SH data. The standard errors of the estimates of $\beta$ are given in parentheses and the standard errors of the regressions are given in brackets. In 
all regressions constant terms are included but the estimates are not reported. Column (1) shows the unconditional $\beta$ convergence estimates. For the sample period as a whole there is evidence of unconditional convergence - the long run single regression of $\beta$ for $1960-90$ is 0.0045 (se $=0.0053$ ). The coefficient is not statistically significant. Table 2 also reports the results of dividing the sample into a number of sub periods. Unconditional convergence is found in four of the sub periods but the $\beta$ coefficient is not significant in any of the estimations. If $\beta$ is restricted to be the same across each sub period while allowing the constant term to vary ${ }^{9}$, the pooled estimate is 0.0028 (se $=0.0035$ ). The coefficient is not significant. However, the hypothesis of equal $\beta$ values across the sub periods can be rejected, so the data may be kept separate. The likelihood ratio statistic is 19.96 with a $p$-value of $0.000^{10}$.

The fact that the coefficient for the sample period as a whole is quite small and statistically insignificant suggests that there are differences between countries other than in the initial level of per capita income. In an attempt to control for cross-country differences equation (2) is also estimated with a number of conditioning variables as outlined in Section III. Column (2) of Table 2 reports the results when the country dummy variable (oil exporting/non-oil exporting) and the sectoral composition variable are added as conditioning variables. The inclusion of the two variables improves the estimates in most periods. For the period 1960-90 there is conditional beta convergence at an annual average rate of 0.76 per cent although the coefficient is not significant. The results for the sub periods reveal conditional convergence in all periods except 1960-65 and 1985-90. $\beta$ is significant at the ten per cent level for 1980-85. Restricting $\beta$ to be the same across all sub periods produces a pooled estimate of 0.0062 (se $=0.0038$ ) which is significant at the ten per cent level. However, as before it is possible to reject the hypothesis of equal $\beta$ values across sub periods; the likelihood ratio statistic is 33.08 with a $p$-value of 0.000 .

The inclusion of three further variables - the population growth rate, the savings rate (measured using real investment spending as a proportion of GDP) and human capital investment serves to raise the convergence rate (see column (3) of Table 2$)^{11}$. For the sample period as a whole the rate of convergence is 1.2 per cent per year on average but the coefficient is not significant. There is convergence in all 
periods except for $1985-90$ and $\beta$ is significant for $1980-85$. The inclusion of these extra variables increases the amount of explained variation in the average growth rate in all cases - in some instances there is a substantial increase in the R-squared value ${ }^{12}$. The pooled estimate is $0.0100($ se $=0.0046)$ which is significant at the five per cent level. Again the hypothesis of equal $\beta$ values across sub periods can be rejected; the likelihood ratio statistic is 62.96 with a $p$-value of $0.000^{13}$.

Table 3 reports the non-linear least squares estimates of $\beta$ using the UN data. The only difference in these estimations is the measure of GDP used. Column (1) shows the unconditional $\beta$ convergence estimates. For the sample period as a whole (1960-97) there is no evidence of unconditional convergence although convergence is present in three of the five year sub periods (and $\beta$ is significant for 1975-80) ${ }^{14}$. Noticeably, the $\beta$ coefficient is smaller for 1960-90 compared with the SH data. The addition of the country dummy variable and the sectoral composition variable raises the convergence rate (see column (2)) when convergence is already present. There is also an increase in the amount of explained variation in the average growth rates. The $\beta$ coefficient is significant for 1975-80. In contrast to the SH data, the inclusion of all of the conditioning variables in equation (2) does not produce a clear pattern in the results. Although there is conditional convergence in four of the sub periods (with the $\beta$ coefficient significant for 1980-85), the convergence rate tends to fall when convergence is already present with the exception of $1980-85^{15}$. For the overall period the addition of the three extra variables makes no difference to the result of no convergence but in other periods the inclusion of these variables works to both eliminate convergence (1960-90) and to generate it (1985-90). In all regressions the explained variation in the average growth rate increases (sometimes appreciably). In line with the cross-sectional estimation conditional convergence is not present in the panel result when all conditioning variables are included and none of the panel estimations are significant. The null hypothesis of equal $\beta$ values across the sub periods is rejected in all three estimations; the likelihood ratio statistic is 32.04 with a $p$-value of 0.000 for the unconditional estimate and 58.78 ( $p$-value 0.000) and 80.42 ( $p$-value 0.000) for the two conditional estimates. 
The change of data set produces a marked difference in the pattern of the results. When all conditioning variables are included the estimates of $\beta$ tend to fall for the UN data (when convergence is already present) while they move in the opposite direction for the SH data set. The convergence estimates are clearly sensitive to the definition of GDP - the lower price of non-traded goods in the poorer countries seem to be better reflected in the SH data. A comparison of the results for comparable time periods is shown in Table 4. In the cases where both data sets identify unconditional beta convergence the SH data produces a higher rate of convergence in three of the four periods. When the dummy variable and the sectoral composition variable are included, the SH data identifies convergence on one more occasion. In the full model the SH data set identifies convergence on more occasions and it produces a higher convergence rate in all periods. In two out of the three panel estimates the SH data produces a higher convergence rate and the only statistically significant estimates.

On the whole the convergence results lend support to the informal 'findings' in Section II - convergence is more likely to be found during those periods when (some) initially poorer countries improve their rank at the expense of richer ones. Although the pattern in the results varies between Tables 2 and 3 there is consistent evidence to suggest that the process of convergence began to weaken in the 1980s before eventually disappearing towards the end of the study period(s). An examination of the relationship between initial income and the average growth in income from the mid-1980s identifies four countries (Haiti, Nicaragua, Uruguay and Chile) as exerting a disproportionate effect on the convergence estimates. Haiti and Nicaragua (both low-income countries) experienced the lowest growth rates of the 19 countries from the mid-1980s while relatively rich Uruguay and Chile grew rapidly in the same period. When these four countries are omitted from the analysis an inverse relationship between initial income levels and average growth rates is revealed - convergence is restored. Growth in Haiti was adversely affected by political strife. Constitutional rule was restored in 1994 and the substantial financial and technical support received from outside helped to promote growth, but the continued poor performance of the agricultural sector in the 1990s damaged the prospects for a sustained recovery. In Nicaragua growth was negative from the early 1980s until the mid-1990s owing to poor policies, adverse external developments and the civil war. The restoration of democracy in 1990 signalled the beginning of a period of structural reform 
(including privatisation and reform of the banking system). Fiscal and monetary policies were

strengthened and foreign exchange and trade systems were liberalised. The programme of reform helped boost per capita GDP to 450 US dollars by the end of the study period - about one-half of its 1980 level [International Monetary Fund, 1998, 1999].

The steady growth in economic activity in Uruguay during the first half of the 1990s stemmed from structural reforms (trade liberalisation, reform of the state, development of the domestic capital market and increased private sector activity) and cautious macroeconomic policies. By 1997 output growth remained strong and inflation had been cut dramatically from the high of 130 per cent 1990 . In Chile the average annual growth rate was 7.7 per cent between 1990 and 1997 while inflation declined gradually from 26 per cent to six per cent in the same period. The strong productivity growth stemmed mainly from structural reforms and an upgrade of the regulations governing the financial system. Despite complications arising from large changes in the terms of trade for part of the 1990s, mainly reflecting variations in world copper prices, performance remained strong to the end of the study period [International Monetary Fund, 2000, 2001].

The results for sigma convergence are shown in Figures 1 and 2. In Figure 1 there is no evidence of sigma convergence for the SH data. The standard deviation rose from 0.226 in 1960 to 0.24 in 1990 - a modest increase of 4.4 per cent. After increasing to 1970 the standard deviation fell to 1985 before rising markedly up to 1990. According to the UN data in Figure 2 there is no evidence of sigma convergence between 1960 and 1997 - the dispersion of per capita incomes between countries has widened ${ }^{16}$. The standard deviation rose from 0.31 at the start of the sample period to 0.35 by 1997 - an increase of 12.7 per cent ${ }^{17}$. However, much of the increase has taken place during the 1990 s when the standard deviation rose appreciably. Following a relatively modest rise in the standard deviation to 1970 the trend was downwards to 1985. In both data sets the dispersion in per capita incomes widened to 1970. From then to the mid-1980s the trend in the standard deviation was downwards ${ }^{18}$. Subsequently the trend has been upwards although for the UN data the standard deviation in 1990 was below that in 1960 . In sum, there is evidence that the cross-country inequality in income has increased over time. 


\section{CONCLUSION}

While there have been numerous studies that have tested the convergence hypothesis in developed regions of the world, very little is known about convergence among groups of developing countries in general and in Latin America in particular. During the period of this study Latin America underwent considerable economic and social change. The reform to the economic structures of the various countries sometimes served to stimulate growth while periods of world recession had the opposite effect. The impact of these changes has not been equally felt in all countries. This is reflected in the patterns of convergence over the period. Between 1960 and 1990 there is evidence of unconditional beta convergence - countries were converging (at a slow speed) to the same level of per capita income. But there is no evidence of sigma convergence for the overall sample period. The distribution of income has not become more equal in Latin America. There is also evidence of conditional convergence to 1990 (SH data) but at a rate that is lower than in many developed country studies. In general convergence rates were highest during the 1970s and early 1980s, while from the mid-1980s convergence disappeared. The case for a proactive regional policy and the strengthening of regional development associations in Latin America seems strong.

It should not be too surprising to find that the rates of beta convergence were highest between 1970 and the mid-1980s. During this time the countries that were originally the vanguard of economic growth failed to achieve their desired rates of accumulation mainly because of their inability to adjust to a changing international environment. Furthermore, the industrialisation programmes introduced by the poorer countries (including the modernisation of the agriculture sector) and the availability of external finance to support productive capacity, served to strengthen convergence (see Section II). However, for most of the 1980s there was an economic crisis and this produced a marked change in the convergence process by the second half of the decade. According to the SH data conditional convergence disappeared in the second half of the 1980s and although still present in the UN data the rate of convergence was considerably smaller than in the first part of the decade. Although the region had returned to moderate growth by the mid-1990s it was still not high enough for countries to revert to their steady state income path. 
The results are sensitive to the measure of per capita GDP. In the estimations with all the conditioning variables, data from the UN identifies convergence less frequently than the data provided by SH while the convergence estimates based on the SH data set are generally higher. The tendency for the SH data to provide higher convergence rates is in line with the findings of Barro and Sal-i-Martin [1995]. In their study of a large sample of developed countries the SH data produced higher estimates than World Bank data. They explain this finding by arguing that poorer countries tend to have relatively low prices for nontraded goods which are more accurately reflected in the SH data set. In the context of this research on Latin America there is no mechanism in the UN calculation of income that allows for cross-country differences in the standard of living - the price of non-traded goods, the underground market and the trade in illegal products are not taken into consideration. 


\section{REFERENCES}

Barro, R.J., 1991, ‘Economic Growth in a Cross Section of Countries’, Quarterly Journal of Economics, Vol. 106, pp. 407-43.

Barro, R.J., and X. Sala-i-Martin, 1991, ‘Convergence across States and Regions’, Brookings Papers on Economic Activity, No. 1, pp. 107-82.

Barro, R.J., and X. Sala-i-Martin, 1992, ‘Convergence’, Journal of Political Economy, Vol. 100, pp. 22351.

Barro, R.J., and X. Sala-i-Martin, 1995, Economic Growth, Boston: McGraw-Hill.

Barro, R.J., Mankiw, N. and X. Sala-i-Martin, 1995, 'Capital Mobility in Neo-Classical Models of Growth', American Economic Review, Vol. 85, pp. 103-15.

Baumol, W.J., 1986, 'Productivity Growth, Convergence and Welfare: What the Long Run Data Show', American Economic Review, Vol. 76, pp. 1072-85.

Choi, H., and H. Li, 2000, ‘Economic Development and Growth Convergence in China', Journal of International Trade and Economic Development, Vol. 9, pp. 37-54.

de la Fuente, A., 2000, ‘Convergence Across Countries and Regions: Theory and Empirics’, CEPR Discussion Paper, No. 2465, May.

Ferreira, A., 2000, ‘Convergence in Brazil: Recent Trends and Long Run Prospects’, Applied Economics, Vol. 32, pp. 79-90. 
Hoffer, H., and A. Worgotter, 1997, 'Regional Per Capita Income Convergence in Austria’, Regional Studies, Vol. 31, pp. 1-12.

Hofman, A., 2000, The Economic Development of Latin America in the Twentieth Century. Cheltenham: Edward Elgar.

International Monetary Fund, 1998, 'Recent Economic Developments in Haiti’, 98/101.

International Monetary Fund, 1999, ‘Recent Economic Developments in Nicaragua’, 99/124.

International Monetary Fund, 2000, ‘Chile: Selected Issues’, 00/104.

International Monetary Fund, 2001, ‘Recent Economic Developments in Uruguay’, 01/47.

Islam, N., 1995, ‘Growth Empirics: A Panel Data Approach’, Quarterly Journal of Economics, Vol. 110, pp. 1127-70.

Islam, N., 1998, ‘Growth Empirics: A Panel Data Approach - A Reply’, Quarterly Journal of Economics, Vol. 113, pp. 325-9.

Khan, M.S., and M.S. Kumar, 1993, 'Public and Private Investment and the Convergence of Per Capita Incomes in Developing Countries’, IMF Working Paper, WP/93/51.

Lee, K., Pesaran, M. and R. Smith, 1997, 'Growth and Convergence in a Multi-Country Empirical Stochastic Solow Model', Journal of Applied Econometrics, Vol. 12, pp. 357-92.

Mankiw, N., Romer, D. and D.N. Weil, 1992, 'A Contribution to the Empirics of Economic Growth', Quarterly Journal of Economics, Vol. 107, pp. 407-37. 
Nagaraj, R., Varoudakis, A. and M.A. Veganzones, 2000, 'Long Run Growth Trends and Convergence across Indian States’, Journal of International Development, Vol. 12, pp. 45-70.

Neven, D., and C. Gouyette, 1995, ‘Regional Convergence in the European Community’, Journal of Common Market Studies, Vol. 33, pp. 47-65.

Pekkala, S., 2000, 'Aggregate Economic Fluctuations and Regional Convergence: The Finnish Case, 1988-1995’, Applied Economics, Vol. 32, pp. 211-19.

Persson, J., 1997, ‘Convergence Across Swedish Counties, 1911-1993’, European Economic Review, Vol. 41, pp. 1835-52.

Quah, D., 1993, 'Galton's Fallacy and Tests of the Convergence Hypothesis’, Scandinavian Journal of Economics, Vol. 95, pp. 427-43.

Quah, D., 1996, 'Empirics for Economic Growth and Convergence’, European Economic Review, Vol. 40, pp. $1353-75$.

Sala-i-Martin, X., 1996a, ‘The Classical Approach to Convergence Analysis’, Economic Journal, Vol. 106, pp. 1019-36.

Sala-i-Martin, X., 1996b, 'Regional Cohesion: Evidence and Theories of Regional Growth and Convergence’, European Economic Review, Vol. 40, pp. 1325-52.

Solow, R.J., 1956, ‘A Contribution to the Theory of Economic Growth’, Quarterly Journal of Economics, Vol. 70, pp. 65-94. 
Terrasi, M., 1999, ‘Convergence and Divergence Across Italians Regions’, The Annals of Regional Science, Vol. 33, pp. 491-510.

United Nations, 1985, 'Crisis and Development in Latin America and the Caribbean’, LC/L, 332.

United Nations, 1996, ‘Open Regionalism: Latin America and the Caribbean in the Global Economy’, LC/R, 1622. 
1. See, for example, Solow [1956]. The model is for a closed economy and assumes diminishing returns to capital, exogenous technical progress and exogenous population growth. Evidence on convergence for open economies (where capital flows across national boundaries) cannot be interpreted in the light of the closed economy model. However, Barro et al [1995] amend the closed model to allow for partial capital mobility and show that the amended model predicts the same type of transitional dynamics as the strict closed economy version.

2. Latin America is as defined by the United Nations and includes the following countries: Argentina, Bolivia, Brazil, Chile, Columbia, Costa Rica, Dominican Republic, El Salvador, Ecuador, Guatemala, Haiti, Honduras, Mexico, Nicaragua, Panama, Paraguay, Peru, Uruguay and Venezuela.

3. Convergence may also arise if there are lags in the diffusion of knowledge. Income differences will arise because some countries are not yet employing the best available technologies but these differences might tend to shrink as poor countries gain access to state of the art methods.

4. Following Barro [1991] and Neven and Gouyette [1995] human capital is defined as the gross enrolment rate in primary education. It is common in cross-country econometric studies for enrolment rates to be used as a rough proxy for education. Another variable of interest is labour migration. The process of convergence ought to be quickened by movements of people out of areas where the ratio of capital to labour is low - and hence wage rates and levels of per capita income are also low - to areas where the ratio is high. Unfortunately data limitations prevent the inclusion of migration as a conditioning variable.

5. Quah [1996] argues that a finding of convergence merely depicts a stationary distribution of incomes rather than a long run tendency for each country to have a steady state growth path. He argues that the study of convergence requires an alternative methodology altogether. Quah sees convergence as a 
transition process across a number of possible states and assumes that it can be modelled as a Markov chain. For a recent application of this approach see Pekkala [2000].

6. An exception is Barro and Sala-i-Martin [1995]. They examine convergence across a number of developed countries using World Bank GDP data as well as GDP data provided by Summers and Heston.

7. Because the two sample periods are not the same, Section IV also includes results for the UN data for 1960-90.

8. One of the main aims of this paper is to examine the sensitivity of the results to alternative measures of per capita income using the 'classical' approach to convergence. While the econometric implications of growth rate heterogeneity is clearly an important issue a detailed examination of the questions raised by Lee et al is beyond the scope of this paper. Also, in contrast to Lee et al, Islam [1998] suggests that allowing for country specific rates of convergence is not a useful economic approach.

9. Based on a likelihood ratio test a pooled model without time effects was rejected (in all cases) in favour of a pooled model with individual constants (time variation).

10. The results proved robust to experimentation with different start dates and to a measure of average income (1955-60) instead of 1960 income. Using years 1961, 1963 and 1965 as start dates instead of 1960 produced overall unconditional convergence estimates of $0.005,0.0048$ and 0.0070 , respectively. The estimate of unconditional convergence for $1955-90$ is 0.0047 . The use of an average income value instead of 1960 income produced an unconditional convergence estimate of 0.0051 . Unconditional convergence estimates are also robust with respect to different end dates. The estimates for 1960-87, 1960-88 and 1960-89 are 0.0043, 0.0037 and 0.0049 , respectively.

11. In some studies growth of the labour force is used instead of population growth rate. The former could not be used here because data were not available for all countries on a consistent basis. It is relatively rare 
for studies to attempt to control for differences in savings rates. Measuring savings in terms of real investment spending as a proportion of GDP follows Mankiw et al [1992]. A measure of human capital investment based on primary enrolment rates proved superior to one based on secondary enrolment rates. It was not possible to use tertiary enrolment rates because of missing data for some countries in most years.

12. Following the convention, and in order to keep Tables 1 and 2 to a manageable size, the coefficients of the conditioning variables are not reported. They are, however, available from the authors on request. The conditioning variables are statistically insignificant in most cases.

13. The results for conditional convergence (all conditioning variables) are also robust with regard to start dates 1961, 1963 and 1965. The figures are 0.0133, 0.0096 and 0.0123, respectively. The figure for conditional convergence (all conditioning variables) using an average income measure (1955-60) is 0.0128. Conditional convergence estimates are somewhat lower with respect to different end dates. The estimates for 1960-87, 1960-88 and 1960-89 are 0.0066, 0.0069 and 0.0067, respectively.

14. It was not possible to use the same alternative start dates as per capita income data is only available on an annual basis from 1970. For the same reason it is not possible to use an average income measure for 1955-60 instead of 1960 income. However, using 1965 as the start date produced a result of no convergence - the coefficient is -0.0008 . Changing the end dates also made no difference to the result of no convergence - the figures for 1960-96, 1960-95 and 1960-94 are -0.0014, -0.0009 and -0.0010, respectively.

15. The result for conditional convergence (all conditioning variables) with 1965 as the start date is 0.0055 - conditional convergence is restored but the coefficient is not significant. The use of different end dates makes no difference to the result of no convergence. The figures for 1960-96, 1960-95 and 1960-94 are $-0.0032,-0.0025$ and -0.0022 , respectively. 
16. The gap in the series in Figure 2 is because GDP per capita data is not available from the UN on an annual basis until 1970

17. The finding that the standard deviation is lower with the SH data set is consistent with the results of Barro and Sala-i-Martin [1995].

18. Ferreria [2000] also finds a narrowing in the dispersion of per capita incomes up to the mid-1980s in his study of regional convergence in Brazil. 


\begin{tabular}{|c|c|c|c|c|c|c|c|c|c|c|c|}
\hline \multirow{2}{*}{ Country } & \multicolumn{2}{|c|}{$\begin{array}{l}\text { Real per capita } \\
\text { GDP (1985 } \\
\text { international } \\
\text { prices) }\end{array}$} & \multicolumn{7}{|c|}{ Rank } & \multirow{2}{*}{$\begin{array}{c}\begin{array}{c}\text { Annual } \\
\text { average } \\
\text { growth } \\
\text { rate }\end{array} \\
1960-90\end{array}$} & \multirow{2}{*}{$\begin{array}{c}\text { Relative } \\
\text { economic } \\
\text { position: } \\
1960 \text { and } \\
1990\end{array}$} \\
\hline & 1960 & 1990 & 1960 & 1965 & 1970 & 1975 & 1980 & 1985 & 1990 & & \\
\hline Argentina & 4462 & 4706 & 2 & 2 & 2 & 2 & 2 & 3 & 3 & 0.17 & MD \\
\hline Bolivia & 1148 & 1658 & 17 & 15 & 15 & 16 & 16 & 17 & 16 & 1.19 & MI \\
\hline Brazil & 1784 & 4042 & 8 & 10 & 9 & 5 & 5 & 4 & 6 & 2.64 & I \\
\hline Chile & 2885 & 4338 & 4 & 5 & 5 & 6 & 6 & 7 & 5 & 1.32 & MD \\
\hline Columbia & 1684 & 3300 & 9 & 11 & 11 & 12 & 10 & 9 & 8 & 2.17 & MI \\
\hline Costa Rica & 2096 & 3499 & 6 & 7 & 6 & 7 & 7 & 8 & 7 & 1.65 & MD \\
\hline Domin Rep & 1195 & 2166 & 15 & 17 & 16 & 15 & 14 & 12 & 12 & 1.92 & I \\
\hline Ecuador & 1461 & 2755 & 13 & 14 & 14 & 9 & 9 & 10 & 10 & 2.05 & I \\
\hline El Salvador & 1427 & 1824 & 14 & 13 & 13 & 14 & 15 & 15 & 15 & 0.79 & MD \\
\hline Guatemala & 1660 & 2127 & 10 & 12 & 12 & 13 & 12 & 13 & 14 & 0.80 & $\mathrm{D}$ \\
\hline Haiti & 924 & 822 & 19 & 19 & 19 & 19 & 19 & 19 & 19 & -0.38 & $\mathrm{U}$ \\
\hline Honduras & 1039 & 1377 & 18 & 18 & 18 & 18 & 18 & 18 & 17 & 0.91 & MI \\
\hline Mexico & 2836 & 5827 & 5 & 4 & 4 & 3 & 3 & 2 & 2 & 2.32 & I \\
\hline Nicaragua & 1606 & 1294 & 11 & 8 & 10 & 10 & 17 & 16 & 18 & -0.70 & SD \\
\hline Panama & 1575 & 2888 & 12 & 9 & 8 & 8 & 8 & 6 & 9 & 1.96 & I \\
\hline Paraguay & 1177 & 2128 & 16 & 16 & 17 & 17 & 13 & 14 & 13 & 1.91 & I \\
\hline Peru & 2019 & 2188 & 7 & 6 & 7 & 6 & 11 & 11 & 11 & 0.26 & D \\
\hline Uruguay & 3968 & 4602 & 3 & 3 & 3 & 4 & 4 & 5 & 4 & 0.48 & MD \\
\hline Venezuela & 6338 & 6055 & 1 & 1 & 1 & 1 & 1 & 1 & 1 & -0.15 & $\mathrm{U}$ \\
\hline LA Average & 2173 & 3031 & & & & & & & & 1.12 & \\
\hline
\end{tabular}

Notes: Real per capita GDP is measured in constant dollars expressed in international prices (base year is 1985). $\mathrm{MD}=$ marginally deteriorated; $\mathrm{MI}=$ marginally improved; $\mathrm{I}=$ Improved; $\mathrm{D}=$ Deteriorated; $\mathrm{U}=$ Unchanged; SD = Significantly deteriorated. 
TABLE 2 CROSS-COUNTRY INCOME GROWTH REGRESSIONS FOR LATIN AMERICA: SH DATA

\begin{tabular}{|c|c|c|c|c|c|c|}
\hline \multirow[b]{2}{*}{ Period } & \multicolumn{2}{|c|}{ Basic equation } & \multicolumn{2}{|c|}{$\begin{array}{l}\text { Equation with country dummy } \\
\text { and sectoral variable }\end{array}$} & \multicolumn{2}{|c|}{$\begin{array}{c}\text { Equation with all conditioning } \\
\text { variables }\end{array}$} \\
\hline & $\begin{array}{c}\text { Beta } \\
(1)\end{array}$ & $\mathrm{R}^{2}$ & $\begin{array}{l}\text { Beta } \\
(2)\end{array}$ & $\mathrm{R}^{2}$ & $\begin{array}{l}\text { Beta } \\
(3)\end{array}$ & $\mathrm{R}^{2}$ \\
\hline $1960-90$ & $\begin{array}{c}0.0045 \\
(0.0053)\end{array}$ & $\begin{array}{c}0.05 \\
{[0.0044]}\end{array}$ & $\begin{array}{c}0.0076 \\
(0.0095)\end{array}$ & $\begin{array}{c}0.06 \\
{[0.0047]}\end{array}$ & $\begin{array}{c}0.0123 \\
(0.0110)\end{array}$ & $\begin{array}{c}0.38 \\
{[0.0043]}\end{array}$ \\
\hline 1960-65 & $\begin{array}{l}-0.0018 \\
(0.0072)\end{array}$ & $\begin{array}{c}0.00 \\
{[0.0071]}\end{array}$ & $\begin{array}{l}-0.0040 \\
(0.0110)\end{array}$ & $\begin{array}{c}0.08 \\
{[0.0072]}\end{array}$ & $\begin{array}{c}0.0035 \\
(0.0136)\end{array}$ & $\begin{array}{c}0.35 \\
{[0.0068]}\end{array}$ \\
\hline 1965-70 & $\begin{array}{c}0.0002 \\
(0.0051)\end{array}$ & $\begin{array}{c}0.00 \\
{[0.0060]}\end{array}$ & $\begin{array}{c}0.0040 \\
(0.0082)\end{array}$ & $\begin{array}{c}0.03 \\
{[0.0063]}\end{array}$ & $\begin{array}{c}0.0070 \\
(0.0078)\end{array}$ & $\begin{array}{c}0.45 \\
{[0.0052]}\end{array}$ \\
\hline 1970-75 & $\begin{array}{c}0.0110 \\
(0.0100)\end{array}$ & $\begin{array}{c}0.06 \\
{[0.0097]}\end{array}$ & $\begin{array}{c}0.0113 \\
(0.0141)\end{array}$ & $\begin{array}{c}0.15 \\
{[0.0098]}\end{array}$ & $\begin{array}{c}0.0210 \\
(0.0171)\end{array}$ & $\begin{array}{c}0.28 \\
{[0.0101]}\end{array}$ \\
\hline 1975-80 & $\begin{array}{c}0.0110 \\
(0.0120)\end{array}$ & $\begin{array}{c}0.05 \\
{[0.0112]}\end{array}$ & $\begin{array}{c}0.0065 \\
(0.0130)\end{array}$ & $\begin{array}{c}0.16 \\
{[0.0111]}\end{array}$ & $\begin{array}{c}0.0214 \\
(0.0160)\end{array}$ & $\begin{array}{c}0.46 \\
{[0.0100]}\end{array}$ \\
\hline 1980-85 & $\begin{array}{c}0.0057 \\
(0.0058)\end{array}$ & $\begin{array}{c}0.06 \\
{[0.0052]}\end{array}$ & $\begin{array}{c}0.0179 \\
(0.0095)\end{array}$ & $\begin{array}{c}0.22 \\
{[0.0051]}\end{array}$ & $\begin{array}{c}0.0228 \\
(0.0117)\end{array}$ & $\begin{array}{c}0.33 \\
{[0.0052]}\end{array}$ \\
\hline 1985-90 & $\begin{array}{l}-0.0098 \\
(0.0093)\end{array}$ & $\begin{array}{c}0.06 \\
{[0.0092]}\end{array}$ & $\begin{array}{l}-0.0190 \\
(0.0148)\end{array}$ & $\begin{array}{c}0.13 \\
{[0.0093]}\end{array}$ & $\begin{array}{l}-0.0161 \\
(-0.0193)\end{array}$ & $\begin{array}{c}0.19 \\
{[0.0100]}\end{array}$ \\
\hline $\begin{array}{l}\text { Panel } \\
\text { estimate }\end{array}$ & $\begin{array}{c}0.0028 \\
(0.0035)\end{array}$ & & $\begin{array}{c}0.0062 \\
(0.0038)\end{array}$ & & $\begin{array}{c}0.0100 \\
(0.0046)\end{array}$ & \\
\hline $\begin{array}{l}\text { LR statistic } \\
\text { (p-value) }\end{array}$ & $\begin{array}{l}19.96 \\
(0.000)\end{array}$ & & $\begin{array}{c}33.08 \\
(0.000)\end{array}$ & & $\begin{array}{c}62.96 \\
(0.000)\end{array}$ & \\
\hline
\end{tabular}

Notes: The standard errors of the estimates are given in parentheses and the standard errors of the regressions are given in brackets. Column (1) reports the coefficient when the only variable held constant is the initial level of per capita income. Column (2) and column (3) report the value of $\beta$ when additional variables are held constant. For the panel estimates all the sub periods are assumed to have the same $\beta$ coefficient. This estimation allows for time effects (individual constants). The likelihood ratio statistic refers to a test of the restriction that $\beta$ is the same over the six sub periods. Under the null, this statistic is asymptotically distributed as chi-squared with 5 degrees of freedom. 
TABLE 3 CROSS-COUNTRY INCOME GROWTH REGRESSIONS FOR LATIN AMERICA: UN DATA

\begin{tabular}{|c|c|c|c|c|c|c|}
\hline \multirow[b]{2}{*}{ Period } & \multicolumn{2}{|c|}{ Basic equation } & \multicolumn{2}{|c|}{$\begin{array}{l}\text { Equation with country dummy } \\
\text { and sectoral variable }\end{array}$} & \multicolumn{2}{|c|}{$\begin{array}{c}\text { Equation with all conditioning } \\
\text { variables }\end{array}$} \\
\hline & $\begin{array}{c}\text { Beta } \\
\text { (1) }\end{array}$ & $\mathrm{R}^{2}$ & $\begin{array}{c}\text { Beta } \\
\text { (2) }\end{array}$ & $\mathrm{R}^{2}$ & $\begin{array}{c}\text { Beta } \\
\text { (3) }\end{array}$ & $\mathrm{R}^{2}$ \\
\hline 1960-97 & $\begin{array}{l}-0.0014 \\
(0.0025)\end{array}$ & $\begin{array}{c}0.02 \\
{[0.0034]}\end{array}$ & $\begin{array}{c}-0.0004 \\
(0.0030)\end{array}$ & $\begin{array}{c}0.05 \\
{[0.0036]}\end{array}$ & $\begin{array}{l}-0.0049 \\
(0.0056)\end{array}$ & $\begin{array}{c}0.42 \\
{[0.0031]}\end{array}$ \\
\hline $1960-90$ & $\begin{array}{c}0.0028 \\
(0.0030)\end{array}$ & $\begin{array}{c}0.05 \\
{[0.0037]}\end{array}$ & $\begin{array}{c}0.0055 \\
(0.0048)\end{array}$ & $\begin{array}{c}0.09 \\
{[0.0038]}\end{array}$ & $\begin{array}{l}-0.0029 \\
(0.0055)\end{array}$ & $\begin{array}{c}0.47 \\
{[0.0033]}\end{array}$ \\
\hline $1960-65$ & $\begin{array}{l}-0.0038 \\
(0.0053)\end{array}$ & $\begin{array}{c}0.03 \\
{[0.0072]}\end{array}$ & $\begin{array}{r}-0.0049 \\
(0.0063)\end{array}$ & $\begin{array}{c}0.05 \\
{[0.0076]}\end{array}$ & $\begin{array}{c}-0.0090 \\
(0.0129)\end{array}$ & $\begin{array}{c}0.32 \\
{[0.0072]}\end{array}$ \\
\hline $1965-70$ & $\begin{array}{l}-0.0061 \\
(0.0049)\end{array}$ & $\begin{array}{c}0.08 \\
{[0.0070]}\end{array}$ & $\begin{array}{c}-0.0124 \\
(0.0048)\end{array}$ & $\begin{array}{c}0.38 \\
{[0.0061]}\end{array}$ & $\begin{array}{l}-0.0076 \\
(0.0055)\end{array}$ & $\begin{array}{c}0.64 \\
{[0.0052]}\end{array}$ \\
\hline $1970-75$ & $\begin{array}{c}0.0050 \\
(0.0070)\end{array}$ & $\begin{array}{c}0.03 \\
{[0.0109]}\end{array}$ & $\begin{array}{c}0.0203 \\
(0.0142)\end{array}$ & $\begin{array}{c}0.23 \\
{[0.0102]}\end{array}$ & $\begin{array}{c}0.0155 \\
(0.0158)\end{array}$ & $\begin{array}{c}0.43 \\
{[0.0098]}\end{array}$ \\
\hline $1975-80$ & $\begin{array}{c}0.0210 \\
(0.0070)\end{array}$ & $\begin{array}{c}0.35 \\
{[0.0093]}\end{array}$ & $\begin{array}{c}0.0215 \\
(0.0064)\end{array}$ & $\begin{array}{c}0.59 \\
{[0.0077]}\end{array}$ & $\begin{array}{c}0.0090 \\
(0.0079)\end{array}$ & $\begin{array}{c}0.77 \\
{[0.0064]}\end{array}$ \\
\hline 1980-85 & $\begin{array}{c}0.0025 \\
(0.0055)\end{array}$ & $\begin{array}{c}0.01 \\
{[0.0089]}\end{array}$ & $\begin{array}{c}0.0076 \\
(0.0088)\end{array}$ & $\begin{array}{c}0.20 \\
{[0.0066]}\end{array}$ & $\begin{array}{c}0.0211 \\
(0.0110)\end{array}$ & $\begin{array}{c}0.48 \\
{[0.0060]}\end{array}$ \\
\hline $1985-90$ & $\begin{array}{l}-0.0039 \\
(0.0070)\end{array}$ & $\begin{array}{c}0.02 \\
{[0.0063]}\end{array}$ & $\begin{array}{r}-0.0048 \\
(0.0076)\end{array}$ & $\begin{array}{c}0.03 \\
{[0.0094]}\end{array}$ & $\begin{array}{c}0.0029 \\
(0.0132)\end{array}$ & $\begin{array}{c}0.11 \\
{[0.0101]}\end{array}$ \\
\hline $1990-97$ & $\begin{array}{l}-0.0160 \\
(0.0040)\end{array}$ & $\begin{array}{c}0.43 \\
{[0.0063]}\end{array}$ & $\begin{array}{l}-0.0167 \\
(0.0045)\end{array}$ & $\begin{array}{c}0.44 \\
{[0.0066]}\end{array}$ & $\begin{array}{c}-0.0084 \\
(0.0072)\end{array}$ & $\begin{array}{c}0.55 \\
{[0.0066]}\end{array}$ \\
\hline $\begin{array}{l}\text { Panel } \\
\text { estimate }\end{array}$ & $\begin{array}{l}0.00007 \\
(0.0024)\end{array}$ & & $\begin{array}{c}0.0013 \\
(0.0025)\end{array}$ & & $\begin{array}{l}-0.00038 \\
(0.0032)\end{array}$ & \\
\hline $\begin{array}{l}\text { LR statistic } \\
\text { (p-value) }\end{array}$ & $\begin{array}{c}32.04 \\
(0.000)\end{array}$ & & $\begin{array}{c}58.78 \\
(0.000)\end{array}$ & & $\begin{array}{l}80.42 \\
(0.000)\end{array}$ & \\
\hline
\end{tabular}

Notes: The standard errors of the estimates are given in parentheses and the standard errors of the regressions are given in brackets. Column (1) reports the coefficient when the only variable held constant is the initial level of per capita income. Column (2) and column (3) report the value of $\beta$ when additional variables are held constant. For the panel estimates all the sub periods are assumed to have the same $\beta$ coefficient. This estimation allows for time effects (individual constants). The likelihood ratio statistic refers to a test of the restriction that $\beta$ is the same over the seven sub periods. Under the null, this statistic is asymptotically distributed as chi-squared with 6 degrees of freedom.

For comparative purposes the panel estimates for the UN data for 1960-90 are 0.0028 (se $=0.0027$ ), 0.0045 (se $=0.0027$ ) and 0.0035 (se = 0.0037) for columns (1)-(3), respectively (see also Table 4). The corresponding LR values are 19.6, 41.74 and 61.24 - all have a $p$-value $=0.000$ 
TABLE 4 COMPARING BETA CONVERGENCE: SH AND UN DATA

\begin{tabular}{rcccccc}
\multicolumn{4}{c}{$\begin{array}{c}\text { Unconditional } \\
\text { convergence }\end{array}$} & \multicolumn{2}{c}{$\begin{array}{c}\text { Conditional convergence: } \\
\text { country dummy and sectoral } \\
\text { variable }\end{array}$} & \multicolumn{2}{c}{$\begin{array}{c}\text { Conditional convergence: } \\
\text { All conditioning variables }\end{array}$} \\
\hline Period & UN data & SH data & UN data & SH data & UN data & SH data \\
$1960-90$ & Yes (0.3\%) & Yes (0.5\%) & Yes (0.6\%) & Yes (0.8\%) & No & Yes (1.2\%) \\
$1960-65$ & No & No & No & No & No & Yes (0.3\%) \\
$1965-70$ & No & Yes (0.02\%) & No & Yes (0.4\%) & No & Yes (0.7\%) \\
$1970-75$ & Yes (0.5\%) & Yes (1.1\%) & Yes (2.0\%) & Yes (1.1\%) & Yes (1.5\%) & Yes (2.1\%) \\
$1975-80$ & Yes (2.1\%)* & Yes (1.1\%) & Yes (2.1\%)* & Yes (0.6\%) & Yes (0.9\%) & Yes (2.1\%) \\
$1980-85$ & Yes (0.2\%) & Yes (0.6\%) & Yes (0.7\%) & Yes* (1.8\%) & Yes (2.1\%)* & Yes (2.2\%)* \\
$1985-90$ & No & No & No & No & Yes (0.2) & No \\
Panel & Yes (0.3\%) & Yes (0.3\%) & Yes (0.5\%) & Yes (0.6\%)* & Yes (0.4\%) & Yes (1.0\%)* \\
estimate & & & & & & \\
\hline
\end{tabular}

Notes: The result for 1990-97 for the UN data is not reported because there is no direct point of comparison with the SH data. The panel estimates reported for the UN data are for $1960-90{ }^{*}=\beta$ is significant at the 10 per cent level or better. 